\title{
PENGEMBANGAN AGROWISATA KOPI BERBASIS MASYARAKAT (CBT) DI KAWASAN GUNUNG GALUNGGUNG KABUPATEN TASIKMALAYA
}

\author{
DEVELOPMENT OF COMMUNITY-BASED COFFEE AGROWITATES (CBT) \\ IN GALUNGGUNG AREA TASIKMALAYA REGENCY
}

\section{Nurhana Jafaruddin*, Trisna Insan Noor, Tuti Karyani}

\author{
Pascasarjana Fakultas Pertanian Universitas Padjajaran \\ Jl. Raya Bandung Sumedang KM.21 Jatinangor, Sumedang, Jawa Barat 45363 \\ *E-mail: jafaruddinnurhana@yahoo.com \\ (Diterima 16-07-2020; Diterima 27-07-2020)
}

\begin{abstract}
ABSTRAK
Kawasan objek wisata Gunung Galunggung di Kabupaten Tasikmalaya memiliki daya tarik wisata bagi wisatawan karena memiliki banyak tujuan dalam satu kawasan wisata. Objek wisata yang berada di kawasan wisata Gunung Galunggung yaitu objek wisata kawah, pemandian air panas, air terjun (curug) serta kedai kopi Shelter Galunggung. Potensi pariwisata Gunung Galunggung belum optimal, antara lain karena belum adanya pengembangan wisata kopi sebagai salah satu objek wisata yang diperkirakan akan menarik wisatawan. Oleh karena itu, seluruh stakeholder sepakat untuk mengimplementasasikan konsep agrowisata berbasis masyarakat di kawasan Galunggung. Tujuan dari penelitian ini adalah untuk menganalisis pengembangan agrowisata kopi berbasis masyarakat di Kawasan Wisata Gunung Galunggung Kabupaten Tasikmalaya. Pengumpulan data dilakukan menggunakan kuesioner berdasarkan sensus. Community Based Tourism (CBT) marupakan wisata yang memperhatikan kelangsungan budaya, sosial dan lingkungan serta didukung oleh partisipasi masyarakat setempat. Aspek ekonomi, sosial, dan lingkungan dianalisis menggunakan indeks rata-rata persepsi masyarakat yang terlibat dalam pengembangan agrowisata kopi. Berdasarkan indeks rata-rata hasil penelitian menunjukkan bahwa agrowisata berbasis masyarakat pada aspek ekonomi dan lingkungan berada di kategori tinggi, sedangkan aspek sosial berada di kategori sangat rendah. Pengembangan agrowisata berbasis masyarakat ini dapat dilakukan dengan meningkatkan aspek yang masih belum optimal yaitu aspek sosial. Perencanaan pengembangan agrowisata berbasis masyarakat ini dapat dilakukan dengan meningkatkan aspek sosial salah satu caranya melalui stakeholder dengan mengadakan FGD secara berkala untuk membahas sejauh mana perkembangan yang sudah dilakukan agar agrowisata kopi berbasis masyarakat secara keberlanjutan dapat tercapai.
\end{abstract}

Kata kunci: Pengembangan, Agrowisata Berbasis Komunitas, Kopi, Kabupaten Tasikmalaya

\section{ABSTRACT}

The tourist area of Mount Galunggung in Tasikmalaya Regency has a tourist attraction for tourists because it has many destinations in one tourist area. Tourist attractions in the tourist area of Mount Galunggung are crater attractions, hot air baths, waterfalls (waterfalls) and Galunggung Shelter coffee shop. The tourism potential of Mount Galunggung is not yet optimal, partly because there is no development of coffee tourism as a tourist attraction that is expected to attract tourists. Therefore all stakeholders must implement the concept of community-based agro-tourism in the Galunggung area. The purpose of this study was to analyze the development of community-based coffee agro-tourism in the Mount Galunggung Tourism Area, Tasikmalaya Regency. Data collection was carried out using a census-based questionnaire. Community Based Tourism (CBT) is a tour that pays attention to culture, social and environment supported by the participation of local communities. Economic, social and environmental aspects are implemented using an average index of perception of the people involved in the development of coffee agro-tourism. Based on the average index the results of the study show that agrotourism is based on economic and 
environmental aspects in the high category, while social aspects are categorized as very low. Development of community-based agro-tourism can be done by improving aspects that are still not optimal, namely social aspects. Planning for community-based agro-tourism development can be done by improving the social aspects of one through stakeholders by involving the FGD as a whole to discuss which developments have been carried out so that community-based coffee agro-tourism can be developed.

Keywords: Development, Community-Based Agrotourism, Coffee, Tasikmalaya District

\section{PENDAHULUAN}

Daerah-daerah yang dianugerahi sumber daya alam yang eksotis, seperti di Jawa Barat diperlukan upaya pengembangan berkelanjutan untuk meningkatkan daya tarik wisatawan domestik maupun mancanegara. Arah pengembangan kawasan wisata ini diharapkan akan mampu memberikan kontribusi terhadap pendapatan asli daerah setempat. Pada saat musyawarah perencanaan pembangunan Provinsi Jawa Barat Tahun 2019 untuk penyusunan Rencana Kerja Pembangunan Daerah (RKPD) tahun 2020, Gubernur Jawa Barat menuturkan sembilan prioritas pembangunan yang akan dilakukan. RKPD yang akan dilakukan salah satu diantaranya adalah melakukan pengembangan destinasi dan infrastruktur pariwisata (Sutrisno, 2019).

Jawa Barat memiliki banyak destinasi wisata yang menarik untuk dikunjungi para wisatawan, salah satunya adalah kawasan Priangan Timur. Salah satu wilayah Priangan Timur yang menawarkan beragam potensi wisata meliputi pegunungan, air terjun, laut, budaya, dan industri kreatif berada di Kabupaten Tasikmalaya (Badan Perencanaan
Pembangunan Daerah Provinsi Jawa Barat, 2017).

Kawasan objek wisata Gunung Galunggung di Kabupaten Tasikmalaya ini memiliki daya tarik wisata bagi wisatawan karena memiliki banyak tujuan dalam satu kawasan wisata. Objek wisata yang berada di kawasan wisata Gunung Galunggung yaitu objek wisata kawah, pemandian air panas, air terjun (curug), kedai kopi Shelter Galunggung, serta sedang dilakukannya penambahan lokasi pengembangan wisata kopi di daerah kawasan wisata Gunung Galunggung.

Perkebunan kopi dan produksi kopi yang ada saat ini masih belum maksimal karena pengelolaan kopi belum dilakukan secara efektif di kawasan wisata Gunung Galunggung. Komoditas kopi ini diharapkan akan bernilai tinggi jika diintegrasikan dengan keindahan Kawasan Galunggung yang mempesona sehingga mempunyai daya tarik kuat sebagai agrowisata.

Potensi pariwisata Gunung Galunggung seharusnya dapat dioptimalkan salah satunya melalui pengembangan wisata kopi berbasis masyarakat di kawasan Galunggung. Upaya tersebut meliputi pembinaan masyarakat dalam mewujudkan 
sinergitas pariwisata dengan pertanian yang dapat menghasilkan pertumbuhan sosial, ekonomi dan organisasi masyarakat (Astuti, 2014).

Upaya pengembangan agwisata kopi berbasis masyarakat dilakukan karena belum adanya strategi pengembangan yang tepat. Menurut Gunn (1994), dalam pengembangan agrowisata harus melibatkan tiga sektor, yaitu sektor usaha yang menyediakan segala keperluan wisatawan seperti jasa transportasi, perhotelan, makanan dan minuman, laundry, serta hiburan. Organisasi seperti organisasi pemuda, organisasi profesi, etnis yang tidak berorientasi pada keuntungan namun memiliki peran dan perhatian besar terhadap pengembangan pariwisata. Sektor pemerintah yang berperan untuk mengeluarkan dan menerapkan undang-undang dan peraturan. Semakin baik pemahaman dan keterlibatan tiga sektor tersebut maka pengembangan agrowisata akan semakin baik. Ketiga sektor tersebut dalam lokasi pengembangan agrowisata kopi penelitian ini masih belum lengkap sektor usahanya seperti belum adanya jasa transportasi, perhotelan atau homestay, toko souvenir dan juga sektor pemerintahnya karena belum adanya peraturan pemerintah setempat secara resmi mengenai agrowisata kopi ini. Oleh karena itu, tujuan penelitian ini adalah untuk menganalisis pengembangan agrowisata kopi berbasis masyarakat di Kawasan Wisata Gunung Galunggung Kabupaten Tasikmalaya sehingga diharapkan dapat meningkatkan pengembangan agrowisata kopi berbasis masyarakat.

\section{METODE PENELITIAN}

Penelitian dilakukan di Desa Linggajati dan Desa Sukaratu Kecamatan Sukaratu Kabupaten Tasikmalaya. Pemilihan lokasi penelitian ditentukan secara sengaja (purposive) dengan pertimbangan bahwa di dua desa tersebut telah melakukan budidaya kopi yang sesuai di ketinggian daerah, yaitu robusta $900 \mathrm{mpdl}$ dan arabica $1.200 \mathrm{mpdl}$, sehingga berpotensi untuk dijadikan agrowisata dan sedang menjadi kawasan rencana pengembangan agrowisata berkelanjutan berbasis kopi oleh pihak pemerintah dan masyarakat setempat.

Metode penelitian yang digunakan adalah metode survei dengan menggunakan kuesioner sebagai alat pengumpulan data. Pengisian kuesioner dilakukan terhadap seluruh stakeholder (sensus) di wilayah penelitian yaitu 142 masyarakat sekitar yang terlibat pengembangan agrowisata kopi.

Untuk menjelaskan keadaan pengembangan agrowisata berbasis masyarakat maka data dianalisis dengan menggunakan analisis deskriptif. Indikator dilihat dengan menggunakan kriteria garis kontinum, yang membagi tanggapan tenaga kerja pemanen responden menjadi 5 kategori (sangat tinggi, tinggi, cukup, rendah dan sangat rendah). Pengkategorian dilakukan dengan berdasarkan pada nilai rata-rata dari jawaban responden. 
Setelah menentukan kriteria dengan metode garis kuantum dan telah didapatkan 5 kriteria pengukuran, kriteria tersebut akan dirubah satuannya ke dalam persentase. Untuk mempermudah pembaca dalam memahami seberapa besar pengembangan agrowisata yang dihasilkan pada peneltian ini. Perubahan satuan kedalam persentase dilakukan dengan membagi hasil indeks ratarata responden dengan jumlah kategori yang telah ditentukan, yaitu 5 kategori lalu dikalikan dengan 100\%. Maka indeks ratarata yang dihasilkan akan memiliki satuan persen. Setelah dilakukan pembulatan maka diperoleh interval kategori dalam bentuk persen sebagai berikut (Riduwan, 2013):

$$
\begin{array}{ll}
23,0 \%-38,4 \% & =\text { Sangat rendah } \\
38,5 \%-53,8 \% & =\text { Rendah } \\
53,9 \%-69,2 \% & =\text { Cukup } \\
69,3 \%-84,6 \% & =\text { Tinggi } \\
84,7 \%-100 \% & =\text { Sangat tinggi }
\end{array}
$$

\section{HASIL DAN PEMBAHASAN}

Definisi wisata berbasis masyarakat atau yang juga dikenal sebagai Community Based Tourism (CBT) sebagaimana dikemukakan oleh Sakti (2012) adalah wisata yang menyadari kelangsungan budaya, sosial serta lingkungan. Menurut Telfer dan Sharpley (2008), pariwisata berbasis masyarakat merupakan salah satu jenis pariwisata yang memasukkan partisipasi masyarakat sebagai unsur utama dalam pariwisata guna mencapai tujuan pembangunan pariwisata berkelanjutan. Sejalan dengan Suansri (2003), aspek utama dalam pengembangan wisata berbasis masyarakat adalah:

1. Ekonomi, dengan indikator timbulnya dana untuk pengembangan komunitas, terciptanya lapangan pekerjaan di sektor wisata dan timbulnya pendapatan masyarakat lokal serta peningkatan produktivitas.

2. Sosial, dengan indikator terdapat peningkatan peran sosial seperti adanya Corporate Social Responsibility (CSR) yaitu sebuah tanggung jawab sosial terhadap lingkungan sekitar dengan apa yang telah dilakukan oleh sebuah perusahaan dalam bentuk berbagai kegiatan, misalnya membangun fasilitas umum, memberikan dana untuk kesejahteraan masyarakat sekitar, budaya lokal yang melekat erat, dan kelembagaan yang menjamin hak-hak masyarakat lokal dalam pengelolaan ssumberdaya alam.

3. Lingkungan, dengan indikator menjaga keanekaragaman hayati, integritas ekosistem atau pengelolaan sumber daya alam berkelanjutan, pengembangan daya dukung lingkungan seperti adanya carryng 
capacity area atau terdapat sistem pembuangan sampah yang ramah lingkungan. Pengelolaan lingkungan ini dilakukan supaya bermanfaat untuk kehidupan generasi mendatang.

Ketiga aspek tersebut sejalan dengan indikator keberlanjutan karena mempunyai indikator yang sama. Melalui konsep wisata berbasis masyarakat maka dapat memberikan gambaran bagaimana masyarakat setempat harus dilibatkan secara aktif dan diberikan kesempatan untuk berpartisipasi. Tujuan akhir yang hendak dicapai adalah meningkatkan kesejahteraan dan kualitas hidup masyarakat itu sendiri. Upaya untuk memberdayakan masyarakat setempat adalah dengan cara partisipasi masyarakat dalam berbagai kegiatan pembangunan wisata termasuk pengelolaan agrowisata.

Pengembangan pariwisata berbasis masyarakat ditujukan untuk meningkatkan pendapatan dan kualitas hidup dari masyarakat lokal, mengembangkan karakter dan perilaku masyarakat lokal yang mendukung bagi pengelolaan potensi sosial budaya dan sumberdaya alam dan lingkungan, mengembangkan pelayanan terhadap wisatawan tanpa merusak atau mengganggu kelestarian sumberdaya lokal (Rashidpour et al, 2010).

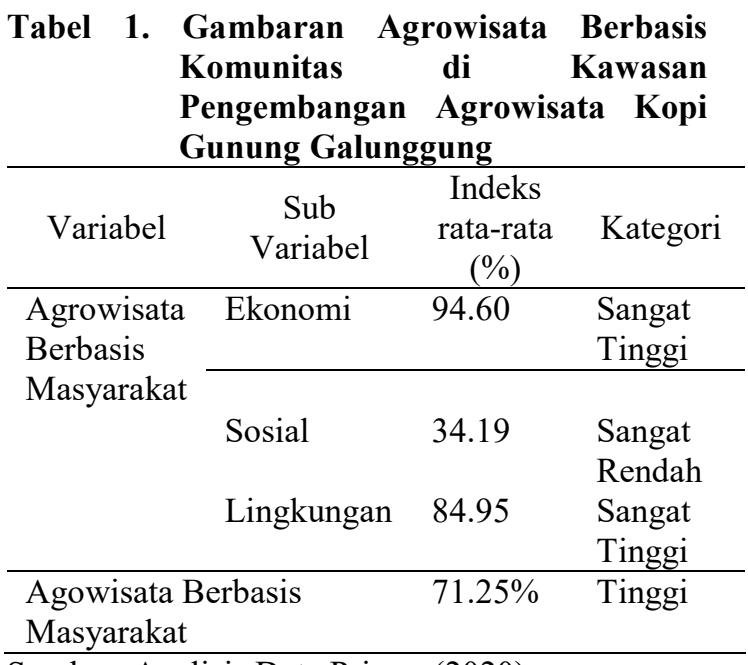

Sumber: Analisis Data Primer (2020)

Dari Tabel 1 dapat dilihat bahwa dari penilaian responden terhadap agrowisata berbasis masyarakat di kawasan pengembangan agrowisata kopi Gunung Galunggung secara keseluruhan termasuk kategori tinggi dengan perolehan indeks rata-rata $71,25 \%$. Jika dilihat dari tiap indikatornya, agrowisata berbasis masyarakat yang memiliki bobot paling tinggi adalah ekonomi dengan indeks rata-rata $94,60 \%$. Indikator yang memiliki persepsi bobot paling rendah yaitu sosial dengan skor 34,19\%. Agrowisata berbasis masyarakat terdiri atas 3 aspek secara keseluruhan dapat digambarkan sebagai berikut:

\begin{tabular}{|c|c|c|}
\hline Agrowisata & Berbasis & Masyarakat \\
\hline Berdasarkan A & pek Ekonomi & \\
\hline Menurut & Sastrayuda & (2010), \\
\hline
\end{tabular}


yaitu memperluas pengetahuan, pengalaman rekreasi, meningkatkan pendapatan masyarakat sekitar dan hubungan usaha di bidang pertanian. Aspek ekonomi dalam penelitian ini berada dalam kategori sangat tinggi dengan nilai indeks rata-rata $94,60 \%$ (Tabel 1). Aspek ekonomi dalam pengembangan agrowisata mendorong produktivitas kopi, peningkatan pendapatan petani, dan peningkatan pendapatan masyarakat sekitar. Adanya pengembangan agrowisata untuk mempersiapkan menjadi suatu agrowisata berbasis masyarakat dengan komoditi kopi dilakukan dengan berbagai cara, salah satunya selalu memberikan edukasi mengenai potensi yang dimiliki untuk dijadikan suatu agrowisata dengan melihat komoditas utama yaitu kopi.

Untuk saat ini adanya camping ground di kawasan pengembangan agrowisata dan berbagai event kopi juga dapat meningkatkan pendapatan masyarakat dan juga petani kopi karena ketika ada acara di camping ground maka pengunjung akan diperkenalkan kopi dari daerah tersebut. Kopi tersebut dijual dengan berbagai pilihan ada yang langsung dikonsumsi dan yang dalam bentuk kemasan sehingga cocok untuk dijadikan oleh-oleh. Harapan masyarakat dan beberapa pihak yang terkait dengan adanya agrowisata kopi nanti dapat menyerap tenaga kerja lokal dan meningkatkan pendapatan masyarakat dan petani kopi. Harapan lainnya juga meningkatkan produtivitas kopi sehingga menjadi kopi unggulan khas Galunggung yang dikenal oleh masyarakat luas.

Menurut Tosun (2000), ada beberapa hambatan dalam pembangunan pariwisata berbasis masyarakat, salah satunya masih minim jumlah sumber daya manusia (SDM) yang berkompeten, minimnya akses modal ekonomi dan rendahnya kesadaran pariwisata masyarakat lokal. Pada penelitian ini salah satu usaha agar mendorong produktivitas kopi dan peningkatan kopi dengan memberikan penyuluhan di bidang kopi dan pendampingan kepada para petani kopi. Pentingnya memberikan pelatihan agrowisata kepada masyarakat sekitar tentang potensi yang dimiliki untuk dijadikan suatu agrowisata, sehingga nantinya akan meningkatkan sumber daya manusia di kawasan pengembangan agrowisata kopi. Adanya program ini nantinya akan membantu masyarakat untuk dapat memanfaatkan berbagai peluang kerja dan berusaha di agrowisata kopi. 


\section{Agrowisata Berbasis Masyarakat}

\section{Berdasarkan Aspek Sosial}

Aspek sosial dalam penelitian ini berada dikategori terendah dengan nilai indeks rata-rata 34,19\% (Tabel 1). Aspek sosial meliputi adanya sosial budaya, sosial yang mendukung pengembangan agrowisata, adanya stakeholder yaitu masyarakat, kelompok tani kopi, Lembaga Masyarakat Desa Hutan (LMDH), Lembaga Pemberdayaan Masyarakat (LPM), pemerintah desa, pemerintah kecamatan, bappeda, dinas pariwisata, perhutani, dinas pertanian, lembaga penyuluhan, pihak swasta, dan perguruan tinggi yang mendukung pengembangan agrowisata.

Budaya yang ada di kawasan pengembangan agrowisata didukung dengan kearifan lokal yang ada misalnya dalam budidaya kopi masih tradisional, agroindustri olahan kopi dan kerajinan tangan. Budaya masyarakat yang ada seperti pancak silat, tari tarian dan juga marawis terus dilestarikan sehingga dapat menjadi daya tarik untuk pengunjung agrowisata kopi nantinya. Sosial budaya yang ada sejalan dan tidak menghambat pengembangan agro wisata kopi. Stakeholder yang ada seperti masyarakat mendukung dan mengijinkan adanya pengembangan agrowisata kopi, kelompok tani kopi, LMDH, LPM, pemerintah desa, pemerintah kecamatan, bappeda, dinas pariwisata, perhutani, dinas pertanian, lembaga penyuluhan, dan perguruan tinggi yang mendukung pengembangan agrowisata.

Stakeholder yang terlibat selalu mendukung adanya pengembangan agrowisata tetapi belum adanya perencanaan agrowisata kopi sesuai dengan aturan pemerintah setempat secara resmi. Hal ini yang menyebabkan aspek sosial menjadi rendah. Kemudian diperkuat oleh Rashidpour et al (2010) yang merekomendasikan bahwa dalam pengembangan agrowisata maka komunitas lokal adalah mitra dan stakeholder yang paling utama. Keterbatasan masyarakat setempat dan stakeholder dalam mendukung pengelolaan agrowisata masih memperlukan campur tangan dari pemerintah.

Untuk stakeholder swasta sebenarnya mendukung pengembangan agrowisata dan sempat menawarkan bantuan agar bisa terealisasi agrowisata kopi, tetapi masyarakat menolak adanya bantuan dari pihak swasta. Masyarakat menggangap apabila nantinya ada bantuan dari pihak swasta masyarakat khawatir akan merasa dirugikan jika ada 
pengelola swasta dan tidak akan memberdayakan masyarakat lokal.

Menurut Sumantra et al (2015), dengan adanya potensi alam, keunikan budaya yang dimiliki, adanya komoditas yang bisa dijadikan peluang untuk agrowisata, adanya partisipasi masyarakat sehingga dapat melibatkan masyarakat sekitar untuk mengelola agrowisata, sudah adanya implementasi dari peraturan pemerintah setempat secara resmi untuk dijadikan agrowisata. Pada penelitian ini terdapat persamaannya yaitu adanya potensi alam, keunikan budaya, pasrtisipasi masyarakat dalam pengembangan agrowisata. Perbedaan dalam penelitian ini peraturan secara resmi dari pemerintah setempat belum ada. Penelitan sebelumnya tidak membahas adanya kerjasama dengan stakeholder, namun dalam penelitian ini membahas adanya kerjasama antara stakeholder dan sudah dijelaskan dalam FGD pertama yang sudah diadakan tetapi memang belum ada kelanjutan FGD.

Terdapat juga persamaan dengan penelitian Septio dan Karyani (2020), yaitu kualitas SDM yang ada masih dirasa belum memadai untuk menjadi pengelola profesional objek wisata, seperti kurangnya penguasaan teknologi, kelembagaan, dan bahasa asing. Pada penelitian ini SDM yang ada saat ini masih sangat rendah dan masih diperlukan peningkatan SDM secara optimal melalui program pelatihan dan pendidikan di bidang agrowisata dan kopi. Peningkatan SDM ini dilakukan agar masyarakat dan juga petani kopi memiliki keterampilan dan kemampuan untuk menjalankan kegiatan usahatani kopi yang maksimal dan juga memanfaatkan peluang agrowisata dengan baik.

\section{Agrowisata Berbasis Masyarakat}

\section{Berdasarkan Aspek Lingkungan}

Aspek lingkungan dalam penelitian ini berada dalam kategori sangat tinggi dengan nilai indeks rata-rata 84,95\% (Tabel 1). Indikator lingukngan meliputi adanya pengembangan agrowisata kopi tidak akan merusak keragaman tanaman yang ada, memperbaiki kondisi lingkungan, menjaga sumber daya alam secara terus menerus dan menyerap limbah ramah lingkungan melalui pengolahan limbah dan sampah kopi (3R). Hal tersebut sesuai dengan keadaan yang ada pada saat ini karena masyarakat sekitar dan juga petani kopi selalu memperhatikan aspek lingkungan. Harapan masyarakat dan beberapa pihak yang terkait dengan adanya agrowisata 
kopi nantinya akan tetap menjaga kondisi lingkungan dengan baik sehingga menjadikan agrowisata kopi yang tetap nyaman bagi masyarakat sekitar dan juga pengunjung.

Menurut Septio dan Karyani (2020) potensi dan daya tarik yang beragam seperti pertanian, perikanan, lingkungan, edukasi, budaya dan kuliner dapat mendukung agrowisata. Konsep back to nature sedang diminati dalam pariwisata termasuk Indonesia. Pada penelitian sudah terdapat beberapa potensi dan daya tarik untuk mendukung agrowisata seperti pertanian yaitu adanya kegiatan budidaya kopi hingga pengolaan komoditas kopi. Lingkungan di kawasan pengembangan agrowisata kopi saat ini sangat terjaga dengan baik dan diharapkan ke depannya konsep back to nature dapat diterapkan.

Penelitian lain yang dilakukan oleh Septio et al (2019) adalah menurut pendapat pengunjung objek wisata yang menawarkan alam dan nuansa pedesaan serta setiap sudut yang indah, baik dari bentuk bangunan, dekorasi dinding, dan penataannya objek wisata. sangat memanjakan pengunjung dan memberikan keindahan tersendiri. Pengembangan agrowisata pada penelitian ini masih membutuhkan penataan lingkungan sehingga nantinya pengunjung dapat merasakan keindahan alam yang ada dan merasa nyaman.

\section{KESIMPULAN DAN SARAN}

Pengembangan agrowisata kopi berbasis masyarakat yang sejalan dengan keberlanjutan dilihat dari 3 aspek, yaitu ekonomi, sosial dan lingkungan. Berdasarkan indeks rata-rata hasil penelitian menunjukkan bahwa agrowisata berbasis masyarakat dengan ekonomi dan lingkungan memiliki indeks rata-rata yang berada di kategori sangat tinggi, sedangkan aspek sosial berada dikategori sangat rendah.

Hal tersebut mengindikasikan bahwa perlunya peningkatan indikator aspek sosial dalam perencanaan agrowisata seperti melalui peningkatan peran stakeholder yang terlibat. Stakeholder mengadakan FGD secara berkala untuk membahas sejauh mana perkembangan yang sudah dilakukan agar agrowisata kopi berbasis masyarakat secara keberlanjutan dapat tercapai. Serta penetapan agrowisata kopi di kawasan wisata Gunung Galunggung Kabupaten Tasikmalaya oleh Pemerintah setempat.

\section{DAFTAR PUSTAKA}

Astuti, M.T. (2014). Potensi Agrowisata Dalam Meningkatkan 
Pengembangan Pariwisata. Jakarta: Kementerian Pariwisata dan Ekonomi Kreatif.

Badan Perencanaan Pembangunan Daerah Provinsi Jawa Barat. (2017). Rencana Besar Pengembangan Destinasi Wisata Kelas Dunia Povinsi Jawa Barat. Bandung: Badan Perencanaan Pembangunan Daerah.

Gunn, C.A. (1994). Tourism Planning. Washington: Taylor and Francis.

Rashidpour, L., Hosseini, S.J.F., Chizari, M. \& Mirdamadi, S.M. (2010). The Pattern of Local Community-Based Mana gement for Sustainable Rural Development in West Azarbaijan Province. American Journal of Agricultural and Biological Sciences, 5(1): 332-337.

Riduwan. (2013). Skala Pengukuran Vaiabel-variabel Penelitian. Bandung: Alfabeta.

Sakti, H.S. (2012). Perencanaan Pariwisata PerDesaan Berbasis Masyarakat (Sebuah Pendekatan Konsep). Yogyakarta: Graha Ilmu.

Sastrayuda, G.S. (2010). Strategi Pengembangan dan Pengelolaan Resort and Leisure Gumelar. Hand out Konsep Pengembangan Kawasan Ekowisata. Melalui http:// file.upi.edu/Direktori/FPIPS/LAIN NYA/GUMELAR S/HAND OUT MATKUL KONSEP RESORT AND_LEISÜRE/PENḠEMBANG AN_AWASAN_DESA_WISATA. pdf. [18/09/19].

Septio, A. dan Karyani, T. (2020). Potensi dan Strategi Pengembangan Kampung Flory Sebagai Kawasan Wisata Berbasis Masyarakat. Jurnal Agroland, 27(1): 45-59.
Septio, A., Karyani, T. dan Djuwendah, E. (2019). Visitors Perception About The Sapta Pesona Implementation In Kampung Flory Sleman Yogyakarta. JBHOST, 05(02): 307-317.

Suansari Potjana. (2003). Community Based Tourism Handbook Thailand. Rest Project. Handbook. Melalui

https://www.mekongtourism.org/w p-content/uploads/REST-CBTHandbook-2003.pdf. [10/10/19].

Sumantra, I.K., Yuesti, A. dan Sudiana, A.A.K. (2015). Pengembangan Model Agrowisata Salak Berbasis Masyarakat di Desa Sibetan. Jurnal Bakti Saraswati UNMAS, 4(2): 156-168.

Sutrisno, D. (2019). Lima Visi dan Sembilan Prioritas Pemprov Jabar Hingga 2023. Jawa Barat : Idn Times Jabar. Melalui https://jabar.idntimes .com/news/jabar/debbiesutrisno/ini-lima-visi-dan sembilanprior itas-pemprov-jabarhingga. [02/09/19].

Telfer, Richard dan Sharpley, David J. (2008). Tourism and Development in the Developing World. New York: Routledge.

Tosun, C. (2000). Limits to Community participation in the tourism development process in developing countries. Turkey: Tourism Management. 